\title{
EL CENTRO DE INTERESES DEL DEUDOR PERSONA FISICA \\ EN EL REGLAMENTO EUROPEO 848/2015 SOBRE PROCEDIMIENTOS DE INSOLVENCIA
}

\author{
CENTRE OF A DEBTOR INDIVIDUAL PERSON'S MAIN \\ INTERESTS ON REGULATION (EU) 2015/848 \\ ON INSOLVENCY PROCEEDINGS
}

\author{
Nerea Magallon Elósegui \\ Profesora Investigadora Ramón y Cajal \\ Universidad del País Vasco (UPV/EHU) \\ ORCID ID: 0000-0003-3994-049X
}

Recibido: 02.12.2020 / Aceptado: 21.12.2020

DOI: https://doi.org/10.20318/cdt.2021.6006

\begin{abstract}
Resumen: El Reglamento (UE)848/2015 ha integrado nuevas pautas para delimitar el centro de intereses principales del deudor que determinaran la competencia internacional a efectos de la apertura de un procedimiento de insolvencia internacional. En este trabajo se examinará si las novedades introducidas ayudan a resolver los obstáculos existentes a la hora de precisar dónde se encuentra dicho centro de intereses principales en los supuestos con un deudor particular. Al hilo de la Sentencia del Tribunal de Justicia de la Unión de 16 de julio de 2020, en el asunto C-253/19, Novo Banco, nos damos cuenta que la presunción que establece el Reglamento en aras a determinar el centro de intereses principales a favor del centro principal de actividad o de la residencia habitual del deudor, para ser realmente operativa, debería ir acompañada de una delimitación más concreta del concepto de deudor y de residencia habitual.

Palabras clave: Reglamento (UE) 848/2015, competencia internacional, centro de intereses principales del deudor, particular que no ejerce actividad comercial o profesional, residencia habitual, destrucción de la presunción.
\end{abstract}

Abstract: Regulation (EU)848/2015 has integrated new guidelines to delimit the centre of a debtor's main interests which will determine the international jurisdiction for the purpose of opening international insolvency proceedings. This paper will examine whether the developments introduced help to reduce the presents obstacles to identifying the centre of main interests in cases involving a private debtor. Concerning Judgment of the European Court of Justice of 16 July 2020, case C-253/19, Novo Banco, we realise that the presumption established by the Regulation to determine the centre of main interests in favour of the main centre of activity or habitual residence is not operational if it is not accompanied by a concrete delimitation of the concept of debtor and habitual residence.

Keywords: Regulation (EU) 2015/848, International jurisdiction, centre of a debtor's main interests, individual not exercising an independent business or profesional activity, habitual residence, rebuttal of the presumption.

*El presente trabajo se adscribe al Proyecto “Mecanismos de Reclamación de DDHH a nivel operativo”; DER 2017-87712R, MINECO y FEDER. 
Sumario: I. Introducción: el Reglamento (UE) 848/2015 sobre procedimientos de insolvencia y el centro de intereses principales del deudor. II. La definición de centro de intereses del deudor persona física: ¿profesional o consumidor? 1. Pautas para determinar el centro de intereses principales de los particulares. 2. Problemas de calificación del deudor particular. III. Elementos para destruir la presunción iuris tantum en el caso de los particulares. 1. El concepto de residencia habitual. 2. El centro principal de actividad. IV. Conclusiones.

\section{Introducción: el Reglamento (UE) 848/2015 sobre procedimientos de insolvencia y el centro de intereses principales del deudor}

1. El Reglamento 848/2015, del Parlamento y del Consejo, de 20 de mayo de 2015 (Reglamento 848/2015), sobre procedimientos de insolvencia modificó el Reglamento 1346/2000 ${ }^{1}$ con el objetivo de hacer frente a los problemas que planteaba su aplicación. Las normas que determinan la competencia judicial internacional para abrir un procedimiento de insolvencia en Europa no se alteran, pero se mejoran con la introducción de algunas aclaraciones dirigidas a concretar, entre otras cosas, el concepto de centro de intereses principales que señala la competencia de los tribunales para llevar a cabo el procedimiento de insolvencia principal ${ }^{2}$.

2. El nuevo texto incorpora novedades que nos van a ayudar a delimitar el centro de intereses principales del deudor cuando desarrolla su actividad económica y/o posee bienes activos en varios Estados. Con ellas procura reducir los obstáculos existentes a la hora de precisar dónde se encuentra realmente el centro de intereses en los supuestos en los que las decisiones estratégicas se toman en un Estado miembro distinto al del lugar donde se localizan los bienes o factores de producción. La delimitación del lugar donde se ubica el centro de intereses se complica cuando no concuerda con el domicilio social de la sociedad concursada, centro de actividad o residencia habitual del particular sujeto a un procedimiento de insolvencia. El Reglamento articula las pautas que deben ser observadas no sólo de cara a establecer el centro de intereses efectivo cuando no coincidan dichos lugares, sino también a evitar traslados fraudulentos dirigidos a sortear la ley aplicable al concurso.

3. En primer lugar, el Reglamento 848/2015 integra en el artículo 3.1. el contenido del Considerando 13 del Reglamento 1346/2000 ${ }^{3}$ completando la definición de centro de intereses principales del deudor en función de la organización o "esfera externa" del deudor ${ }^{4}$. Con ello, en cierto modo, establece las prioridades a tener en cuenta a la hora de identificar el centro de intereses principales efectivo del deudor poniendo el acento en cómo se manifiesta su presencia de cara al mercado y a sus acreedores.

4. En segundo lugar, incorpora presunciones iuris tantum que incrementan la seguridad jurídica de la norma y que, salvo prueba en contrario, señalan como centro de intereses principales al domicilio social en el caso de las sociedades y personas jurídicas, al centro principal de actividad de las personas físicas que ejercen una actividad mercantil o profesional independiente y a la residencia habitual respecto a los demás particulares (consumidores). Recordamos que el Reglamento 1346/2000 únicamente aludía a la presunción a favor del domicilio social referida a las sociedades y personas jurídicas, creando un desequilibrio funcional respecto al deudor persona física superado por el nuevo texto.

${ }^{1}$ Reglamento (UE) 848/2015, de 20 de mayo de 2015, sobre procedimientos de insolvencia, DOUE 5 de junio de 2015, $\mathrm{n}^{\circ}$ L 141. Reglamento 1346/2000 del Consejo de 29 de mayo de 2000, DOUE 30 de junio 2000, $\mathrm{n}^{\circ}$ L60.

${ }^{2}$ F. Garcimartin Alferez, "El nuevo Reglamento europeo de insolvencia (III): competencia judicial internacional, en https://almacendederecho.org/el-nuevo-reglamento-europeo-de-insolvencia-iii-competencia-judicial-internacional

${ }^{3}$ La ubicación de la definición de centro de intereses en el Preámbulo del Reglamento 1346/2000 se debe al objetivo de respetar la redacción del texto del Convenio comunitario de Insolvencia de 1995 que no llegó a entrar en vigor, pero incorporando aquellos aspectos del Informe Explicativo sobre el mismo realizado por Virgós/Schmit entre los que destaca la definición de centro de intereses. Vid., $\mathrm{n}^{\mathrm{o}}$ marg. 75, del Informe Virgós/Scchmit sobre el Convenio relativo a los procedimientos de insolvencia anexo a M. Virgos/F. Garcimartin, Comentarios al Reglamento Europeo de Insolvencia, Thomson-Civitas, Madrid, 2003.

${ }^{4}$ M. Virgos/F. Garcimartin, Comentario...loc. cit., p. 49. 
5. La Sentencia del Tribunal de Justicia de la Unión (STJUE) de 16 de julio de 2020, as. C-253/19, Novo Banco, que ha motivado este trabajo, nos ofrece la posibilidad de examinar si las novedades sobre el centro de intereses principales aportadas por el Reglamento 848/2015 cumplen sus expectativas y nos dotan de herramientas válidas para delimitarlo cuando el deudor se trate de una persona física. El TJUE ha tenido la oportunidad de analizar en varias ocasiones la definición de centro de intereses del deudor persona jurídica ${ }^{5}$, sin embargo, es la primera vez desde la promulgación del nuevo Reglamento que se le requiere para acotar la definición de centro de intereses principales cuando el deudor es un particular. Así, con el objetivo de estudiar las nuevas pautas otorgadas en la determinación del criterio competencial, al hilo de la Sentencia europea, abordaremos la noción de centro de intereses principales del deudor persona física o particular en el Reglamento 848/2015 (II) y, a continuación, estudiaremos las presunciones añadidas a este respecto y las posibles circunstancias a utilizar para su prueba en contrario (III).

\section{La definición de centro de intereses principales del deudor persona física: ¿profesional o con- sumidor?}

\section{Pautas para determinar el centro de intereses principales de los particulares}

6. La presencia de diversas soluciones para establecer el criterio o foro de competencia judicial internacional en materia de insolvencia transfronteriza ${ }^{6}$ viene indisolublemente unida a la existencia de dos grandes modelos de ordenación concursal marcados por sendos principios de "unidad y universalidad" y "pluralidad y territorialidad"7. De hecho, la elección del centro de intereses como criterio o foro de competencia judicial internacional en materia de concurso del Reglamento 848/2015 (así como de su predecesor el R1346/2000), al igual que su definición, se debe a la opción adoptada por el legislador europeo y las cuestiones en torno a su determinación se ven afectadas, en gran medida, por la solución híbrida recogida en el Reglamento 848/2015.

7. El legislador europeo durante la elaboración del Reglamento 1346/2000, se inclinó por una solución basada en los principios de "universalidad y pluralidad", denominada "universalismo mitigado", que apostaba por un modelo de insolvencia transfronteriza cimentado en el concurso universal o principal, pero que no prescinde de la posibilidad de abrir procedimientos territoriales o secundarios. Con ello se busca alcanzar el equilibrio entre la realización de los fines esenciales del concurso acorde a una adecuada cooperación internacional y la protección de los intereses locales afectados.

8. Conforme a esta primera pauta, las normas de competencia judicial del Reglamento 848/2015 se apoyan en un foro flexible de carácter material para señalar la competencia de los tribunales respecto al concurso principal: el centro de intereses principales del deudor; y lo combinan con otro más rígido que le sirve de correctivo para los supuestos de concursos territoriales: el establecimiento del deudor. En este trabajo nos vamos a centrar en cómo acotar el lugar donde se encuentra el centro de intereses principales del deudor.

9. El criterio "centro de intereses principales" escogido por el Reglamento 848/2015 sigue al Reglamento 1346/2000 que a su vez lo tomó del Convenio europeo de Estambul de 5 de junio 1990 sobre ciertos aspectos de la quiebra ${ }^{9}$. Con esta opción el Reglamento 1346/2000 se alejaba levemente

\footnotetext{
${ }^{5}$ Sentencia de 2 de mayo de 2006, as. C- 341/04, Eurofood; Sentencia de 20 de octubre de 2011, as. C-396/09, Interdil.

${ }^{6}$ Vid., C. Espluges Mota, La quiebra internacional, Bosch, Barcelona, 1993.

${ }^{7}$ Tal y como ponía de manifiesto, J. GonZÁLEZ CAmpos, “Aspectos internacionales de la situación concursal” en La reforma del Derecho de quiebra, Civitas, Madrid, 1982, pp. 329-402, p. 337.

${ }^{8}$ Cifr. M. Virgos/F. Garcimartin, Comentario...loc. cit., p. 25; L. Carballo Piñeiro, "El Reglamento (CE) nùm. 1346/2000, de 29 de mayo de 2000, sobre procedimientos de insolvencia, Instrumentos europeos de Derecho Internacional Privado", Cuadernos de Derecho Judicial, 2011, (obra cedida por la autora).

${ }^{9}$ No alcanzo las ratificaciones necesarias para entrar en vigor.
} 
del Proyecto de Convenio entre los Estados miembros de la CE sobre quiebra, concordatos y procedimientos análogos de 1980 que utilizaba un criterio de competencia con el mismo objetivo, pero excesivamente vinculado a las personas jurídicas o sociedades: "el centro de administración social" ${ }^{\text {. }}$. El criterio designado por ambos Reglamentos es un poco más amplio y alude igualmente a la administración central de los intereses del deudor, pero con un carácter neutro y abierto, de modo que puede ser aplicado a cualquier deudor sin distinguir su naturaleza de persona física o jurídica ${ }^{11}$. A pesar de ello, se le debe dotar de un contenido preciso. La expresión "intereses" comprende las actividades económicas de los particulares así que no son solo actividades comerciales, industriales y profesionales, sino todo tipo de actividades económicas incluyendo las de los consumidores. Recordamos que este concepto también fue adoptado por la Ley Modelo UNCITRAL sobre insolvencia transfronteriza de $1997^{12}$.

10. El carácter integrador, pero excesivamente flexible de centro de intereses principales del deudor ha sido considerado también como su mayor debilidad ${ }^{13}$. Y es que comporta una serie de desventajas inherentes a la necesidad de concretarlo caso por caso, en función de las circunstancias del deudor, que vamos a tener la ocasión de comprobar a través de la presente Sentencia del TJUE, en la que surgen discrepancias vinculadas, esencialmente, a la ausencia de una definición más precisa.

11. Con el objetivo de mitigar los problemas procedentes de mencionada flexibilidad (dilatación del proceso y dificultad de la prueba) y de dotar de cierta uniformidad al concepto, el Reglamento $848 / 2015$ en primer lugar, asienta las bases para su delimitación y, en segundo lugar, establece una serie de presunciones que señalarán el lugar de centro de intereses principales iuris tantum en caso de duda.

12. A tenor del articulo $3.1 \mathrm{R} 848 / 2015$, el centro de intereses principales del deudor será "el lugar en el que el deudor lleve a cabo de manera habitual y reconocible por terceros la administración de sus intereses" en calidad de "conexión real" con un determinado Estado. Con ello, el Reglamento 848/2015 dota de prevalencia al lugar desde donde se dirige y se gestiona el negocio, profesión, empresa o patrimonio del deudor, frente al lugar de producción o lugar de operaciones y frente a la conexión patrimonial o lugar donde se encuentran los activos. Además, la certeza en torno a ese lugar se mide en función del grado de previsibilidad que concede a los potenciales acreedores, así que dependerá de la forma de manifestarse del deudor hacia el exterior y en sus relaciones con terceros. El "elemento externo" permite a los acreedores identificar ex ante la jurisdicción competente (y la ley aplicable) en caso de concurso del deudor y valorar el riesgo concursal que está asumiendo ${ }^{14}$. En definitiva, el termino habitual denota idea de normalidad y continuidad; y del principio de apariencia se extrae la seguridad suficiente para prever los riegos que asumen los futuros acreedores ${ }^{15}$.

13. Por otra parte, con la finalidad de facilitar la localización del lugar al que corresponde el "centro de intereses" principales y de reducir las dificultades probatorias en caso de duda, el Reglamento establece una serie de presunciones iuris tantum que admiten prueba en contra. La presunción de centro de intereses establecida para los particulares se añade como novedad en el Reglamento 848/2015, ya que no aparecía en el texto del Reglamento anterior, aunque sí se tuvo en cuenta en el Informe Virgós/Schmit

\footnotetext{
${ }^{10}$ J. D. GonzÁlez CAmpos, “Aspectos internacionales...”, op.cit., p. 340.

${ }^{11}$ J.D. GonzÁlez CAmpos, Diversification, spècialisation, flexibilisation et materialisation des règles de droit international privé, RCADI, 2000, pp. 9-426, p. 245; A.L. Calvo Caravaca - J. Carrascosa González, "Procedimientos de insolvencia y Reglamento1347/2000: ¿Cuál es el “centro de intereses principales del deudor?”, en Cuestiones actuales de Derecho mercantil internacional, A. L. Calvo Caravaca y S. Areal Ludeña (dres.), Colex, Madrid, 2005, pp. 217-240, p. 224.

${ }^{12}$ Vid., artículo 2.b Ley Modelo UNCITRAL sobre insolvencia transfronteriza, de 1997, y punto 72 de la Guía para la incorporación al Derecho interno de la Ley modelo.

${ }^{13}$ M. Virgos/F. Garcimartin, Comentario...loc. cit., p. 46.

${ }^{14}$ Vid., J.D. González Campos, Diversification..., loc.cit., p. 245; A.L. Calvo Caravaca y J. Carrascosa GonzÁlez, "Procedimientos...", op.cit., p. 227; F. Garcimartin AlfERez, "El nuevo Reglamento europeo de insolvencia (III): competencia judicial internacional, en https://almacendederecho.org/el-nuevo-reglamento-europeo-de-insolvencia-iii-competencia-judicialinternacional

${ }^{15}$ M. Virgos/F. Garcimartin, Comentario...loc. cit., p. 49-50.
} 
sobre el Convenio de Bruselas relativo a los procedimientos de insolvencia de 23 de noviembre de 1995 que le sirve de precedente y en Ley Modelo UNCITRAL sobre insolvencia transfronteriza de $1997^{16}$.

En el caso de los particulares, la norma diferencia entre aquellos que realizan una actividad mercantil o profesional independiente cuyo centro de intereses principales se presumirá que es su centro principal de actividad, de "otros particulares" para los que señala a su residencia habitual.

14. Como vemos, la distinción entre ambos tipos de presunciones parte de la diferente naturaleza del deudor particular que, a su vez, está basada en el tipo de actividad que desarrolla y depende de si ejerce o no una actividad profesional. A pesar de ello, el Reglamento 848/2015 no define ni la noción de actividad profesional independiente, ni los conceptos de centro principal de actividad y residencia habitual.

La Sentencia del TJUE en el as. Novo Banco en cierto modo refleja las posibles dudas que pueden surgir en la aplicación práctica de ambos conceptos y la presencia de estas dudas, nos van a servir de baremo para evaluar la eficacia de las nuevas presunciones establecidas en el texto ${ }^{17}$. No podemos olvidar que los conceptos integrados en el Reglamento europeo precisan de una definición autónoma que garantice su aplicación uniforme y que, al mismo tiempo, deberá ser lo suficientemente específica para responder a las particularidades del Reglamento 848/2015 ${ }^{18}$.

\section{Problemas de calificación del deudor particular}

15. En la Sentencia del TJUE en el as. Novo Banco se entrevé que las dificultades derivadas de la interpretación del criterio "centro de intereses principales del deudor" cuando se trata de particulares pueden venir ligadas, en parte, a la falta de definición de las nociones de deudor y de residencia habitual del Reglamento 848/2015. De hecho, lo primero que se debe plantear en relación a la decisión del TJUE que traemos a colación es el tipo de deudor ante el que nos encontramos puesto que en su calificación como particular que no realiza una actividad mercantil o profesional independiente parecen encontrarse la mayor parte de los problemas que se vislumbran bajo las aparentes incoherencias de esta decisión.

16. Los antecedentes de hecho de la decisión europea señalan como protagonistas a un matrimonio residente en Reino Unido que presenta solicitud de apertura de concurso ante los tribunales portugueses. El tribunal portugués de primera instancia declaró que carecía de competencia internacional para resolver su solicitud porque consideraba que el centro de intereses principales de los deudores conforme al artículo 3.1. R848/2015 correspondía a su lugar de residencia. Basó su decisión en que los demandantes eran particulares que trabajaban por cuenta ajena y, por tanto, utilizó la presunción de la residencia habitual como centro de intereses principales del deudor particular que no ejerce actividad profesional para declinar su competencia.

17. El matrimonio, no conforme con esa decisión, interpuso recurso contra la Sentencia de Instancia ante la Audiencia de Guimarães en Portugal (el órgano jurisdiccional que remite la cuestión prejudicial al TJUE) alegando que, aunque tuvieran su residencia habitual en el Reino Unido donde trabajan por cuenta ajena, todos los contratos y negocios que originaron su insolvencia se resolvieron en Portugal y allí se halla el único bien inmueble que conforma su patrimonio; de modo que no hay

${ }^{16}$ Vid., $\mathrm{n}^{\mathrm{o}}$ marg. 75, del Informe Virgós/Scchmit sobre el Convenio relativo a los procedimientos de insolvencia anexo a M. Virgos/F. Garcimartin, Comentarios al Reglamento Europeo de Insolvencia, Thomson-Civitas, Madrid, 2003; Ley Modelo UNCITRAL sobre insolvencia transfronteriza de 30 de mayo 1997, y Guía para la incorporación al Derecho interno de la Ley modelo: https://uncitral.un.org.

17 "La determinación de la residencia habitual de una persona física plantea los mismos problemas probatorios que la determinación de su centro de intereses principales. Por ello, para cualquier parte interesada viene a ser lo mismo probar dónde se encuentra el centro de los intereses principales, tal y como se define en el Reglamento que probar dónde se encuentra su residencia habitual", como dice F. Garcimartin Alferez, "El nuevo Reglamento...", op.cit., p. 2.

${ }^{18}$ Sentencia de 2 de mayo de 2006, as. C-341/04, Eurofood, apartado 31 y Sentencia de 20 de octubre de 2011, C-369/09, as. Interdil, apartado 43; vid., L. Calvo Caravaca y J. Carrascosa González, "Procedimientos...”, op.cit., p. 227. 
conexión alguna entre su actual residencia y los hechos que generaron la insolvencia que se produjeron íntegramente en ese Estado. En virtud de tales circunstancias, los recurrentes solicitaban se tuviera en cuenta el Considerando 30 del R848/2015 que establece que tratándose de personas que no ejercen una actividad mercantil profesional o independiente se podrá destruir la presunción a favor de la residencia, por ejemplo, en el supuesto, en que la mayor parte de los bienes del deudor esté situada fuera del Estado miembro en el que reside habitualmente. Ante las diferencias planteadas, la Audiencia portuguesa interpone una cuestión prejudicial al TJUE dirigida a especificar si la existencia de un bien inmueble en un Estado distinto al del lugar de residencia del deudor es suficiente para abrir el procedimiento de insolvencia de un nacional que tiene su residencia habitual en otro Estado miembro.

18. El problema que debemos resolver antes de verificar si hay razones para desvirtuar la presunción del Reglamento 848/2015 a favor de la residencia habitual en el caso de particulares que trabajan por cuenta ajena es si, realmente, nos encontramos ante este tipo de deudores. Se trata de una duda que, como hemos visto, no fue tenida en cuenta ni por el Tribunal de Instancia portugués, ni por los propios recurrentes, pero en la que, sin embargo, se encuentra la clave para realizar una fundamentación sólida y acorde con el espíritu del Reglamento 848/2015 sobre la competencia de los tribunales portugueses.

19. El TJUE tampoco repara en tal necesidad; y el Abogado General en sus Conclusiones la descarta excesivamente rápido a través de dos puntos de sus apreciaciones iniciales que acotan el contenido de la cuestión prejudicial. Nos extraña que el Abogado General, a pesar de que subraya que la petición de la cuestión prejudicial de la Audiencia portuguesa no precisa las disposiciones del Reglamento cuya interpretación se solicita, tome la firme decisión de atender únicamente al análisis del artículo 3.1. R848/2015 párrafos primero y cuarto, prescindiendo de su posible relación con el párrafo segundo (apartado 20). En esta misma dirección, deja bien claro que "no se discute que los recurrentes están comprendidos en esta categoría de personas" ${ }^{19}$ (en referencia a particulares que no ejercen actividad mercantil o profesional) asentando unas premisas que marcan el contenido del resto de sus argumentaciones y que llevan aparejada una decisión que se aleja de los hechos reales del supuesto y que, finalmente, no se adapta a la controversia suscitada. Normalmente las disonancias entre los problemas que subyacen a una cuestión prejudicial y la decisión del TJUE se deben a la manera de formular la pregunta por parte de los tribunales estatales, pero en este supuesto la determinación de la respuesta parece venir marcada por las decisiones al respecto adoptadas por el Abogado General ${ }^{20}$.

20. No cabe duda de que los protagonistas del concurso que solicitan su apertura ante los tribunales portugueses son un matrimonio de particulares que trabaja por cuenta ajena y reside en el Reino Unido, a pesar de ello, surge otra cuestión acerca de su naturaleza como deudores. El inconveniente deriva del traslado de residencia habitual de los particulares que lleva aparejado, paralelamente, un cambio en el ejercicio de su actividad y, por tanto, en su condición de deudor; puesto que en Portugal (antes del traslado), realmente, sí realizaban actividad mercantil o profesional independiente y, tal y como alegan, todos los contratos y negocios que han dado lugar al concurso se vinculaban a dicha actividad.

21. El TJUE con anterioridad ha tenido la ocasión de pronunciarse en torno al momento en el que fijar el centro de intereses principales del deudor en caso de traslado, resolviendo que deberá atenderse al tiempo de la solicitud de la apertura del concurso $^{21}$, pero no sabemos en qué instante calificar

\footnotetext{
${ }^{19}$ Conclusiones del Abogado General Sr. Maciej Szpunar, presentadas el 30 de abril de 2020, as. C-253/19, Novo Banco, apartado 12.

${ }^{20}$ La cuestión prejudicial planteada por la Audiencia de Guimarães dice así: "En virtud del Reglamento n. ${ }^{\circ} 2015 / 848$ del Parlamento Europeo y del Consejo, ¿son competentes los tribunales de un Estado miembro para proceder a la apertura del procedimiento de insolvencia principal de un nacional que tiene en dicho Estado su único bien inmueble, aunque su residencia habitual, así como la de su núcleo familiar, esté situada en otro Estado miembro, en el que desarrolla una actividad profesional por cuenta ajena?".

${ }^{21}$ L. CARBallo Piñeiro, "El traslado del centro de los intereses principales del deudor (a propósito de la STJUE StaubitzSchreiber), ADCo, vol. 9., 2006, pp. 497-519.
} 
la naturaleza del deudor, a pesar de que se trata de un tema esencial cuando de esa calificación puede depender, como se desprende en este supuesto, la determinación de su centro de intereses principales y como consecuencia la competencia de los tribunales para llevar a cabo el procedimiento.

22. Si retomamos la definición de centro de intereses principales del deudor del art. 3.1. R848/2015 descubrimos que las presunciones establecidas en los párrafos siguientes de ese mismo artículo se dirigen a fortalecer las pautas instauradas al inicio de su tenor, y están planteadas para ayudar a identificar, en casos complicados, el lugar donde el deudor lleva a cabo de manera habitual la administración de sus intereses conforme a criterios objetivos comprobables por terceros; así que deben constituir el punto de partida en su interpretación.

Al proyectar estas premisas sobre el supuesto controvertido se nos plantea la duda acerca del grado de objetividad y la posibilidad de comprobación que van a tener los acreedores del centro de intereses de nuestros protagonistas cuando la actividad económica y la administración de la actividad económica que causó la situación de insolvencia se encuentra, claramente, en un lugar distinto al de su residencia habitual. Esta divergencia, en cierto modo, disminuye la seguridad jurídica de sus acreedores a la hora de prever el órgano jurisdiccional competente (y la ley aplicable) para abrir un hipotético y futuro procedimiento de insolvencia e, incluso, podría quedar definitivamente mermada si finalmente se acude al tribunal de la residencia en vez de al lugar del centro principal de actividad de los deudores que constituye el vínculo real en relación con sus acreedores ${ }^{22}$. Si así fuera, se rompería la primacía de la esfera externa que impide al deudor oponer a los terceros un lugar distinto de aquel desde el cual aparece de cara al mercado como lugar desde el que administra su empresa de manera habitual.

23. Consiguientemente, que la residencia habitual y el centro de actividad económica difieran puede depender de dos posibilidades: que se haya producido un traslado "simple" de la residencia habitual del deudor, o que se haya producido un traslado de la residencia del deudor y una alteración de la naturaleza de su condición. En el supuesto que nos ocupa la clave definitiva se halla en la modificación añadida en la naturaleza del deudor.

Con carácter general en el caso de que un profesional (empresario o comerciante individual) tenga su residencia habitual en un Estado y su centro profesional o establecimiento principal en otro, el foro de competencia se basará en el segundo criterio cuando esas actividades profesionales sean el origen del procedimiento concursal. Sin embargo, en el supuesto de un particular que tiene su residencia habitual en un Estado miembro y su trabajo dependiente en otro distinto se tomará el primero como centro de intereses ${ }^{23}$. Ahora bien, si se produce un traslado de la residencia del deudor y una alteración en su naturaleza se rompe el elemento de continuidad entre la conexión formal y la conexión real que nos llevan a priorizar la conexión real.

Si proyectamos todo lo anterior sobre el as. Novo Banco concluimos que se ha roto la continuidad de la conexión con el foro por lo que deberíamos atender a la naturaleza del deudor previamente a que se produjera dicha ruptura, y ello nos lleva a entender que los deudores con anterioridad a su cambio de residencia eran particulares que realizaba actividades mercantiles o profesionales así que, en consecuencia, su centro de intereses principales se debe presumir que recae en su centro principal de actividad donde se llevaron a cabo las actividades profesionales que dieron lugar a la insolvencia y que están ligados a los “intereses principales” relacionados con la actividad del deudor, es decir en Portugal.

\footnotetext{
${ }^{22}$ Un caso similar podría plantearse en el caso de que se produzca una reorganización y el deudor ya no sea el que tiene el centro de intereses, sino la entidad encargada de la reorganización (argumento utilizado en la Guía para la incorporación al derecho interno y la interpretación de la Ley Modelo de la CNUDMI sobre insolvencia transfronteriza al analizar la fecha de la determinación del centro de intereses y el establecimiento (apartados 157-160).

${ }^{23}$ Vid., Moss /Smith en The EC Regulation on Insolvency Proceedings: a commentary and annoted guide, Moss/ Fletcher/Isaacs (ed.), 2002, p. 169. A Commentary and Annotated Guide, Oxford University Press, Oxford, 2002, pp. 35-44.
} 


\section{Elementos para destruir la presunción iuris tantum en caso de particulares}

24. El Reglamento 848/2015 ha introducido dos presunciones distintas establecidas para delimitar el centro de intereses principales de los particulares en función de si ejercen, o no, una actividad mercantil o profesional. Si el deudor es un particular que realiza una actividad por cuenta propia se presume que su centro de intereses principales es, salvo prueba en contra, el centro principal de actividad y para el resto de los particulares el de su residencia habitual.

25. Las presunciones se instauran para facilitar la aplicación del criterio elegido en caso de duda despejando las incógnitas acerca del tribunal competente. Se convierten en un elemento dirigido a dotar de mayor seguridad jurídica a las partes que prevalecerá salvo prueba en contrario. De esta forma, aunque se admite prueba en contra, la carga probatoria recae sobre la parte que quiera destruir la presunción y si no hay elementos suficientes a favor de la localización del centro de intereses principales en otro Estado distinto predominará lo señalado por la presunción ${ }^{24}$.

Esto último ha sucedido en el asunto Novo Banco en el que el TJUE ha dotado de prevalencia a la presunción a favor de la residencia habitual de los recurrentes como centro de intereses particulares y ha descartado que la existencia de un bien inmueble en un Estado distinto fuera un elemento suficiente para desarticular tal presunción, manteniendo que se debe hacer una valoración conjunta de las circunstancias de hecho. Pero ¿qué circunstancias se han tenido en cuenta que no imperan sobre la presunción?

26. El tipo de elementos o circunstancias que se van a utilizar para determinar el centro de intereses principales también dependerá de si el deudor es particular que ejerce una actividad mercantil profesional o si es un particular que trabaja por cuenta ajena. El Considerando 30 del Reglamento 848/2015 establece que las presunciones deben ser "refutables" y que corresponde al órgano jurisdiccional competente valorar "cuidadosamente" si el centro de intereses del deudor está realmente situado en ese Estado. A tales efectos indica que la presunción a favor de la residencia habitual en el caso de particulares que no realizan una actividad profesional podrá ser descartada, por ejemplo, si la mayor parte de los activos del deudor están situados en un Estado distinto del lugar de su lugar de residencia (y es la argumentación en la que se han apoyado los recurrentes). Sin embargo, no especifica nada acerca de la presunción a favor del centro principal de actividad de los particulares que ejercen actividad mercantil o profesional independiente.

27. Para valorar la eficacia de la presunción deberemos tener en cuenta que los elementos o circunstancias que han servido para establecer que la residencia o el lugar donde se encuentra el centro principal de actividad se refiere al centro de intereses principales del deudor particular serán los mismos que nos van a ayudar a verificar si realmente conexión formal y conexión real coinciden. Por tanto, bajo los elementos o circunstancias que pueden destruir las presunciones del Reglamento 848/2015 se halla implícita la definición del concepto de residencia habitual y/o centro principal de actividad propia del Reglamento.

\section{El concepto de residencia en el Reglamento 848/2015}

28. El concepto de residencia no está definido por el Reglamento 848/2015. Se ha dicho que la laguna es voluntaria y sirve para conservar un concepto de residencia lo más amplio posible en el que puede tener cabida cualquier fórmula ${ }^{25}$, así que su delimitación dependerá de los distintos elementos que rodean a la situación caso por caso.

29. El TJUE ha tenido ocasión de pronunciarse sobre la residencia en atención a otros instrumentos de Derecho Internacional privado vinculados a aspectos del Derecho de familia ${ }^{26}$. Aún así, es

\footnotetext{
${ }^{24}$ M. Virgos/F. Garcimartin, Comentario...loc. cit., p. 51.

${ }^{25}$ F. J.Ault-SeSEKe y D. Robine, “Le Règlement 848/2015...”, op.cit., p. 32.

${ }^{26}$ Reglamento (CE) 2201/2003, de 17 de noviembre de 2003, relativo a la competencia, reconocimiento y la ejecución
} 
menester destacar, que en materia de insolvencia el elemento patrimonial juega un papel fundamental a diferencia de datos referidos a la situación social o familiar utilizados en otros contextos. Como ha subrayado el Abogado General (apdos. 45 y 19) ${ }^{27}$, los criterios pertinentes para determinar el centro de intereses principales de un particular que no ejerce actividad mercantil o profesional independiente son los relativos a su situación patrimonial y económica, lo que corresponde con el lugar donde esa persona lleva a cabo la administración de sus intereses económicos y en el que percibe y gasta la mayoría de sus ingresos, o el lugar en el que se encuentran la mayor parte de sus activos.

29. La presencia o situación de los bienes del deudor en el lugar donde se solicita la apertura del procedimiento utilizada por los recurrentes para defender la competencia del tribunal portugués es un foro de competencia habitual en los sistemas que parten del principio de "pluralidad y territorialidad". Realmente, la presencia de los bienes debe existir en el momento en el que solicita la apertura del concurso con el objetivo de proceder a su liquidación y pagar fácilmente a los acreedores locales. Ahora bien, aunque la ubicación de los bienes del deudor es uno de los criterios objetivos reconocibles por terceros que deben intervenir para determinar dónde se lleva a cabo la administración de sus intereses, la presunción a favor de la residencia habitual solo puede destruirse conforme a una valoración conjunta de todas las circunstancias del caso. Tal y como ha establecido el TJUE, el hecho de que el único bien inmueble de los deudores esté situado fuera del Estado miembro en el que residen habitualmente no es por sí sola presunción suficiente y habrá que valorar el resto de los elementos que rodean al supuesto para indicar si el centro de intereses principales efectivo se sitúa en dicho Estado.

30. No obstante, los recurrentes han puesto a disposición del Juzgado de Instancia y de la Audiencia portuguesa otros elementos pertinentes en aras de defender la competencia del tribunal portugués y la ubicación de su único bien inmueble en Portugal no es la única razón aludida para abogar por abrir el procedimiento en ese Estado. También alegaron que era el lugar donde se habían llevado a cabo los negocios y se habían celebrado los contratos que provocaron la insolvencia (es frecuente que los contratos entre los "terceros" y los "deudores" se celebren en el lugar donde se encuentra la "sede de dirección" 28 ). A este respecto el TJUE establece (apdo. 30) que la causa de la situación de insolvencia tampoco es por sí misma, una circunstancia oportuna para determinar el centro de intereses principales de un particular que no ejerce actividad mercantil o profesional independiente y que, en todo caso, corresponde al tribunal remitente considerar todas las circunstancias objetivas reconocibles por terceros relativas a su situación patrimonial y económica.

El foro de la "actividad negocial" ha sido utilizado frecuentemente por el sistema concursal francés e inglés. La realización de una actividad mercantil en el territorio de un Estado, por parte de un deudor extranjero, podría justificar la atribución de la competencia judicial internacional para abrir el concurso si partimos de la caracterización de las leyes concursales como leyes de "policía y seguridad" o de "orden público" que se imponen en su territorio. Se trata de una justificación coherente basada en la protección del comercio y del crédito que ha podido obtener el deudor en ese Estado ${ }^{29}$. Pero también es característico de los sistemas basados en la pluralidad y territorialidad del concurso y, por tanto, está planteado desde la hipótesis de la apertura de varios procedimientos. Una vez más, procede deducir que por sí solo tampoco es suficiente para destruir la presunción establecida en el Reglamento 848/2015 basado en el principio de universalidad (aunque en este caso no se pone en duda la unidad del procedimiento).

31. En virtud de todo lo anterior, concluimos que la presunción a favor de la residencia habitual no cumplirá sus objetivos cuando no concuerde con el lugar donde se toman las decisiones económicas de un deudor, como lugar en el que percibe y gasta la mayoría de sus ingresos o como lugar en el que

de resoluciones judiciales en materia matrimonial y de responsabilidad parental, por el que se deroga el Reglamento (CE) 1347/2000, Sentencia de 22 de diciembre de 2010, as. C-497/10, B. Mercredi vs. Chaffe.

${ }^{27}$ Conclusiones del Abogado General Sr. Maciej Szpunar, presentadas el 30 de abril de 2020, as. C-253/19, Novo Banco.

${ }^{28}$ Como subrayan, L. Calvo Caravaca - J. Carrascosa González, "Procedimientos...”, op.cit., p. 227.

${ }^{29}$ J. D. GonZÁlez CAMpos, “Aspectos internacionales...”, op.cit., pp. 344-345. 
se sitúa la mayor parte de sus activos y que, en todo caso, corresponderá al órgano jurisdiccional remitente considerar si el hecho de que el único bien inmueble constituye la mayor parte de sus activos se encuentre en otro Estado puede destruir la presunción a favor de la residencia, siempre en relación con las demás circunstancias que rodean al supuesto.

32. En este supuesto, creemos que los recurrentes han aportado suficientes elementos de hecho que tomados en su conjunto hubieran servido al Tribunal portugués para estimar la destrucción de la presunción a favor de la residencia. Sin embargo, hay un dato definitivo que resulta decisivo si nos remitimos a las circunstancias objetivas reconocibles por terceros relativas a su situación patrimonial y económica y es que todos los negocios y contratos que originaron la situación de insolvencia se concluyeron en Portugal y son los únicos que desarrollaron los recurrentes como particulares que ejercían una actividad mercantil o profesional. Si apostamos por la esfera externa del deudor y el "principio de apariencia" en su relación con los "terceros" y/o acreedores cobraría mayor relevancia dicha actividad para determinar su centro de intereses que la que hubieran realizado posteriormente como particulares que trabajaban por cuenta propia.

De hecho el Abogado General también reparo en esta circunstancia y, a pesar de ello, concluyó que "en lo tocante a los particulares que no ejercen una actividad por cuenta propia, no se debe otorgar una importancia decisiva a la impresión global producida anteriormente por la situación de un deudor respeto a sus acreedores", puesto que lo relevante será tener en cuenta los elementos objetivos que puedan ser comprobados en el momento de la presentación de la solicitud (apartados 49 y 50) ) $^{30}$ lo que no tuvo en cuenta es que se ha producido una modificación en la naturaleza del deudor que rompe la continuidad implícita necesaria para poder sostener esa afirmación al delimitar su centro de intereses efectivo.

33. En la decisión en torno al as. Novo Banco la naturaleza del deudor como particular que no ejerce actividad mercantil o profesional ha marcado las pautas a las que atender para destruir la presunción del Reglamento 848/2015 pero ¿qué hubiera sucedido si se hubiera calificado al deudor como un particular que realiza una actividad mercantil o profesional?

\section{El centro principal de actividad}

34. El centro principal de actividad tampoco está definido en el Reglamento 848/2015 y no aparece en el Considerando 30 instaurado para esclarecer el significado de las presunciones a favor del domicilio social, centro principal de actividad y residencia habitual de su artículo 3.1. El centro principal de actividad tomado como "centro de intereses principales" debe corresponder, igualmente, al lugar desde donde se toman las decisiones que afectan a las actividades económicas del deudor, es decir la "sede de dirección". Indudablemente, pueden existir "otros intereses" que afectan al deudor pero debemos recordar que el Reglamento 848/2015 se refiere a los intereses principales, es decir ligados a la esfera económica fundamental del deudor $\mathrm{y}$, de este modo, excluye otro tipo de intereses familiares o personales ${ }^{31}$.

35. Siguiendo esta orientación el centro de intereses principales de las personas físicas que sean profesionales corresponde con su centro principal de actividad o "domicilio profesional" 32 . El Reglamento 848/2015 presume que donde se encuentra el centro principal de actividad, es decir donde se realiza la mayor parte de la actividad económica se encuentra su sede de dirección o centro de intereses principales. Por tanto, en el caso que ha dado lugar a la decisión del TJUE en el as. Novo Banco el centro principal de actividad de los recurrentes hubiera señalado Portugal como centro de intereses principales si se hubieran calificado como particulares que realizan una actividad mercantil o profesional

\footnotetext{
${ }^{30}$ Conclusiones del Abogado General Sr. Maciej Szpunar, presentadas el 30 de abril de 2020, as. C-253/19, Novo Banco.

${ }^{31}$ L. Calvo Caravaca - J. Carrascosa González, "Procedimientos...", op.cit., p.229.

${ }^{32}$ Termino propuesto en el Informe Virgós/Scchmit sobre el Convenio relativo a los procedimientos de insolvencia, $\mathrm{n}^{\circ} \mathrm{marg}$. 75, anexo a M. Virgos/F. Garcimartin, Comentarios al Reglamento Europeo de Insolvencia, Thomson-Civitas, Madrid, 2003.
} 
36. En los supuestos en los que la dirección de la "empresa" se realice, realmente, desde otro Estado y no corresponda con su domicilio profesional o centro de actividad principal cabe la posibilidad de prueba en contra y, entonces deberá valorarse "cuidadosamente" por el órgano jurisdiccional dependiendo de las circunstancias concretas de cada caso. La conclusión a la que llegamos es que, en caso de duda, se requerirá una valoración global del juez de los elementos pertinentes que rodean al supuesto y que las presunciones establecidas por el Reglamento 848/2015 no siempre facilitarán ni aligerarán la carga de la prueba ${ }^{33}$.

\section{Conclusiones}

37. El Reglamento 848/2015 incorpora algunas novedades que delimitan la definición de centro de intereses principales del deudor con el objetivo de facilitar su localización y evitar traslados fraudulentos dirigidos a sortear la ley aplicable.

38. Para ello traslada a su artículo 3.1. la definición de centro de intereses del deudor anteriormente situada en el Considerando 13 del Reglamento 1346/2000. De esta forma, se confirma que la ubicación de las pautas para delimitar el criterio escogido en el Preámbulo del Reglamento 1346/2000 era algo coyuntural y, su introducción en el articulado del texto, reafirma las prioridades interpretativas que debemos tener en cuenta para situar el lugar donde se encuentra el centro de intereses principales del deudor cuando desarrolle su actividad económica en varios Estados. Así, en consonancia con los principios de unidad y universalidad, prevalecerá el lugar desde donde se lleva a cabo las decisiones de dirección y de estrategia económica tomado como criterio único y constatable por terceros en aras a señalar la competencia de los tribunales para abrir el concurso.

39. A pesar de lo anterior, el criterio escogido por el Reglamento 848/2015 para señalar la competencia en materia de insolvencia tiene un carácter abierto que debe ser matizado y llenado de contenido. Para dotar de mayor uniformidad al concepto de centro de intereses y ayudar a agilizar la carga probatoria en los casos controvertidos el Reglamento 848/2015 introduce presunciones que señalan cuál va a ser ese centro de intereses salvo prueba en contrario.

40. Las presunciones a favor del centro principal de actividad y de la residencia habitual como centro de intereses principales en el caso de los particulares que realizan una actividad profesional y de los consumidores es incorporada como novedad en el texto del Reglamento 848/2015, y en este trabajo hemos tenido la oportunidad de analizar su eficacia al hilo de la STJUE en el as. Novo Banco. La decisión del TJUE, utilizada como eje vertebrador del trabajo, nos ha ayudado a poner de manifiesto que la definición de los conceptos de "deudor particular", de "centro principal de actividad" o de "residencia habitual" en el Reglamento 848/2015 conlleva el mismo grado de dificultad probatoria que la inherente al centro de intereses principales que pretende dilucidar, lo que nos lleva a concluir que, las presunciones en materia de particulares, apenas aligeran la carga de la prueba.

41. Como hemos visto, en los supuestos en los que se haya producido un traslado del domicilio o residencia habitual del deudor se incrementan las dificultades para delimitar su centro de intereses principales y se complica la tarea del órgano jurisdiccional que deberá comprobar de oficio, en base a todas las circunstancias que rodean al supuesto si, tras el traslado, coinciden la conexión real y la conexión formal establecida para ubicarlo.

42. Por otra parte, el traslado de domicilio o residencia en el caso de particulares, puede llevar aparejada la modificación del lugar desde donde se lleva a cabo la dirección estratégica de la actividad económica o la alteración de la naturaleza del deudor que ha podido cambiar de tipo de actividad y, por

${ }^{33}$ Como resalta, F. Garcimartin Alferez, “El nuevo Reglamento...”, op.cit., p. 2. 
tanto, de calificación. La calificación del deudor como particular que realiza una actividad mercantil profesional o como consumidor se convierte en un dato esencial en los supuestos en los que se plantean dudas acerca de lugar donde se ubica el centro de intereses principales del deudor, sobre todo al utilizar las nuevas presunciones de Reglamento 848/2015 y establecer los elementos que las destruyen.

El Reglamento 848/2015 no especifica a qué instante debemos atender para realizar la calificación del deudor. Y el momento en el que se solicita la apertura del procedimiento utilizado para concretar el centro de intereses principales parece inadecuado cuando el cambio de naturaleza del deudor se ha producido con anterioridad. No obstante, corresponderá al TJUE pronunciarse sobre este tema porque, aunque hubiera tenido ocasión de hacerlo en la decisión sobre el as. Novo Banco, ha optado por el camino fácil y apenas lo ha pasado de soslayo. 